Organisation, establishing a national drugs list, importing generic drugs at low cost, and ensuring proper storage and distribution.

A further objection to the scheme is the almost inevitable deterioration of rational prescribing: paying patients will see it as their right to demand drugs and injections, which may be inappropriate; and health staff will be under pressure to prescribe if their salary depends on drug profits.

Unicef recognises the enormous problems of implementing the policy, yet its solutions and strategies remain vague. Community management of revolving drug funds is dealt with by initial training courses, but there is no commitment to continued support and evaluation locally. Unicef still expects to scale up schemes rapidly in participating countries to nationwide implementation; yet suddenly introducing the initiative with so many changes and little attention to detail is likely to be counterproductive. Unicef has been criticised before for dreaming up global solutions organised from the top down.

Much basic spade work must be done locally to ensure that the scheme is properly understood. Other sources of funding - whether through risk sharing, insurance schemes, or taxation - need to be considered.$^{8}$ Host governments should commit themselves to continued financial and supervisory input and to maintaining control over their own health services. Avenues of communication between participating staff and governments need to be established and maintained to share the experiences of financing schemes. Gradual and sensitive introduction, with careful monitoring of equity, utilisation, and rational drug use from the outset, is essential to prevent failure of this important proposal.

Research Fellow,

PAUL GARNER

Evaluation and Planning Centre for Health Care,

London School of Hygiene and Tropical Medicine,

London WC1E 7HT

1 Kanji N. Charging for drugs in Africa: UNICEF's "Bamako initiative." Health Policy and Planning 1989; : $110-20$.

2 Grant JP. Africa: the Bamako initiative. In: Unicef. The state of the world's children 1989. Oxford: Oxford University Press, 1989:50.

3 Anonymous. The Bamako initiative [Editorial]. Lancet 1988;ii:1177-8.

4 Chabot J. The Bamako initiative. Lancet 1988;ii:1366-7.

5 Unicef. The Bamako initiative. New York: Unicef, 1988. (Mimeograph E/ICEF/1988/P/L40.)

6 Waddington CJ, Enyimayew KA. A price to pay: the impact of user charges in Ashanti-Akim district, Ghana. International fournal of Health Planning and Management 1989;4:17-47.

Wisner B. GOBI versus PHC? Some dangers of selective primary health care. Soc Sci Med 1988;26:963-9.

8 Hoare (i. Policies for financing the health sector. Health Policy and Planning 1987;2:1-16.

\title{
Improving the results of treating gastric cancer
}

\section{Demands earlier diagnosis and better surgery}

In England and Wales about 10000 people die each year from carcinoma of the stomach, ${ }^{1}$ and at diagnosis only about $1 \%$ of cases are early (carcinoma confined within the submucosa). ${ }^{2}$ The Japanese, motivated by having an incidence of the disease about three times that in Britain, have increased the proportion of cases of the disease that are diagnosed early from $2 \%$ in $1955^{3}$ to $30 \%$ in $1978 .{ }^{+}$By adhering to a set of rules for describing the condition and its stage ${ }^{5}$ they have made possible accurate assessment of results. Their widespread use of extended lymphadenectomy is now well known: in this procedure (known as R2 resection) an extra "tier" of lymph nodes is removed in addition to those close to the stomach that are normally removed in a conventional gastrectomy (known as $\mathrm{R} 1$ resection). The merits of this operation have not yet been proved by a controlled trial, but its use has yielded much valuable information about lymph node metastasis.

Nodes containing tumour are often not enlarged or hard, so that up to three quarters of them are impossible to detect macroscopically. ${ }^{67}$ The tumour is identified only by painstaking dissection of fresh specimens obtained at gastrectomy and careful histological examination by the methods described in the Japanese rules. If this is not done understaging may occur. In Japan lymph node metastases are present in about one in seven of early cases; with increasing invasion by the tumour into and then out of the gastric wall this proportion increases and the prognosis worsens. ${ }^{+}$About a third of patients in whom the serosa has been reached have metastatic tumour in their lymph nodes. ${ }^{+}$When the serosa is penetrated the proportion rises to four fifths, and over a third of the affected nodes are in the second tier (known as N2 nodes) ${ }^{+5}$; this is beyond the reach of the standard resection in Britain. Most patients in Britain present with the serosa already penetrated, and in over $80 \%$ the lymph nodes have been affected. ${ }^{8}$

The results of treatment in Japan have not been equalled elsewhere. Of 5959 new cases of gastric cancer that were assessed after five years in 1978, resections had been per- formed in $4605(77 \%)$ and extended lymphadenectomy in 3673 ( $80 \%$ of resections). The age corrected five year survival after resection was $81 \%$ for patients with lesions confined within the serosa (with or without disease in the lymph nodes) and $30 \%$ for those with more advanced disease. ${ }^{+}$Overall survival after resection was $60 \%$, and the 30 day postoperative mortality was under $2 \%$. $^{+}$These results are challenging when compared with the British age corrected five year survival of $4 \%$. $^{2}$ Survival in Britain was improved to only $17 \%$ by resection, which was possible in only $27 \%$ of cases. ${ }^{2}$

We do not know the relative contributions to the better results of early diagnosis and better surgery; nor do we know whether the Japanese disease behaves in a less aggressive way than the British version. The remarkable improvement in early diagnosis in Japan has gone hand in hand with improved survival. ${ }^{3}$ The main advaittage of extended lymphadenectomy may lie in its use in patients who have disease in only the first tier of lymph nodes (N1 nodes): the five year survival in such patients is $26 \%$ in those who have had the conventional operation and $63 \%$ in those who have had an extended lymphadenectomy. ${ }^{+}$The apparently normal N2 nodes removed by the extended lymphadenectomy may contain micrometastases that are not detectable even by the Japanese methods. The data must be interpreted with caution, however, because histologically detectable disease in the second tier of nodes may have been missed by the conventional resections. But an extended resection in Japan cures a third of patients who have cancer in the second tier of nodes, and a conventional resection is fruitless in such patients. Most of the cures were, however, in patients whose disease had not passed through the serosa. ${ }^{+}$Such patients (serosa negative, N2 positive) are rarely encountered at present in Britain. Data are scanty on the effect of the type of operation on patients with serosal invasion. Four fifths of the Japanese patients in this category had cancer cells only on the surface of the serosa, and a third of this group survived five years. Only $17 \%$ of those with infiltration into surrounding tissue survived five 
years. ${ }^{+}$The figure is similar in Britain after less radical resection, ${ }^{2}$ and in Britain we may well be dealing mostly with patients whose disease has infiltrated into surrounding tissue.

The early disease in Japan may be different from that in Britain because the survival in Japanese patients (95\%) is so much better than that in British patients (70\%) that it cannot be explained purely on the basis of removing more affected nodes - and even $\mathrm{R} 1$ resection in Japan still produces an $88 \%$ five year survival. ${ }^{24}$ Nearly half of the few early lesions that are encountered in Britain are type III lesions (excavated and mimicking benign ulcers) compared with less than $5 \%$ in Japan, which again suggests a different type of early disease. ${ }^{2+}$ Another difference may be that only $16 \%$ of Japanese patients have lesions in the cardia (which carry a poorer prognosis stage for stage than those in the body and antrum) compared with $30 \%$ in one series reported from Britain. ${ }^{+9}$

The British Medical Research Council is now running a trial to compare extended lymphadenectomy with conventional gastrectomy. Eligible cases are those up to the Japanese stage III, in which the liver and peritoneum are clear of the disease but the serosa has been breached or there is metastasis to the second tier of lymph nodes ${ }^{5}$ (MRC cooperative surgical trial for gastric cancer, protocol, Ninewells Hospital, Dundee). In Japan patients with stomach cancer are younger than in Britain; in addition, the Japanese have less obesity and a lower incidence of arterial disease, and postoperative deep vein thrombosis is almost unknown. There will inevitably be a learning curve for surgeons undertaking the tricky dissection of friable, haemorrhagic fat and lymphatic tissue close to vital structures. It may also be difficult to set aside the extra operative time needed without the service to other patients deteriorating.

Despite these difficulties we need to identify which, if any, patients in Britain will benefit from an extended lymphadenectomy, and the MRC trial should achieve this. But diagnosis of the condition also needs attention. Some encouraging results have come from the West Midlands, where 48 new cases of gastric cancer were detected among 2820 patients with dyspepsia who were screened; eight of these were early cases (A Jewkes, meeting of the British Stomach Cancer Group, Manchester, 1988). This approach screens only patients with symptoms, but in Japan also most patients have symptoms. The resource implications of repeatedly screening all patients aged over 50 with dyspepsia are daunting, but only with a drive toward early diagnosis and, probably to a lesser extent, better surgery may the results of treating gastric cancer be improved. And the Japanese have shown that improvement is possible.

PETER J MILEWSKI

Withybush Hospital, Consultant in General Surgery

Haverfordwest,

Pembrokeshire SA61 2PZ

University Department of Surgery,

JOHN BANCEWICZ Reader in Surgery

Hope Hospital,

Salford M6 8HD

1 Office of Population Censuses and Surveys. Deaths by cause. London: HMSO, 1986.

2 Fielding JWL, Ellis DJ, Jones BG, et al. Natural history of "early" gastric cancer: results of a 10 yea regional survey. BrMed f 1980;281:965-7.

3 Miwa K. Cancer of the stomach in Japan. GANN Monograph on Cancer Research 1979;22:61-75.

4 Miwa K. Report of treatment results of stomach carcinoma in fapan. Tokyo: National Cancer Center 1978. (Japanese Research Society for Gastric Cancer monograph.)

5 Japanese Research Society for Gastric Cancer. The general rules for the gastric cancer study in surgery and pathology. Jpn $\mathcal{X}$ Surg 1981;11:127-45.

6 Okamura T, Tsujitani S, Korenaga D, et al. Lymphadenectomy for cure in patients with early gastric cancer and lymph node metastasis. Am $\mathcal{F}$ Surg 1988;155:476-80.

Okaiima K. Surgical treatment of gastric cancer with special reference to lymph node removal. Acta Med Okayama 1977;31:369-82.

8 Fielding JWL, Roginski C, Ellis DJ, et al. Clinicopathological staging of gastric cancer. Br $\mathcal{F}$ Surg 1984;71:677-80.

9 Paterson IM, Easton DF, Corbishley CM, Gazet JC. Changing distribution of adenocarcinoma of the stomach. Br $\mathcal{F}$ Surg 1987; 74:481-2.

\section{Birth asphyxia and cerebral palsy}

\section{Birth asphyxia is hard to define and measure but is rarely the cause of cerebral palsy}

Most laymen and many obstetricians and paediatricians believe that cerebral palsy could be prevented by better obstetric care. Not surprisingly, perinatal brain damage has become an important reason for litigation, which will cause increasing problems for health authorities in the next few years.

\section{Terminology}

Cerebral palsy is not a single entity. It may be defined as "a disorder of posture or movement which is persistent but not necessarily unchanging, and is caused by a non-progressive lesion of the brain, acquired at a time of rapid brain development." It may be, but is not always, accompanied by other neurological impairments such as mental retardation, cortical vision defects, or epilepsy.

The movement disorder may be predominantly spastic, ataxic, or athetoid; it may affect any number and combination of limbs, head, and trunk; there are many recognised causes and many cases in which the cause is not apparent. The causes of cerebral palsy are traditionally divided into prenatal, perinatal, and postnatal.
Mental retardation may result from perinatal or postnatal factors, but in most children with mental retardation unaccompanied by cerebral palsy the cause is prenatal ${ }^{1}$ - for example, chromosomal defects, other anomaly syndromes, or noxious influences as in the fetal alcohol syndrome. People with mental retardation commonly show a delay in motor maturation so that they are late to walk and run, but their pattern of motor development is otherwise normal. The term "cerebral palsy" implies that motor function is not merely delayed but is also deviant - that is, following a course never seen in a normal child.

\section{Epidemiology}

As cerebral palsy is not a single entity and authors vary in their case definitions and completeness of ascertainment, the data on incidence and prevalence are inexact. Estimates vary from two to four cases for every 1000 births. Mental retardation occurs in about $3 \cdot 7$ children in every 1000 births. There is little evidence of any recent decline in the incidence of either cerebral palsy or mental retardation despite improved obstetric standards. ${ }^{2}$ 